\title{
Oesophageal varices, schistosomiasis, and mortality among patients admitted with haematemesis in Mwanza, Tanzania: a prospective cohort study
}

Awilly A Chofle ${ }^{1 *}$, Hyasinta Jaka ${ }^{1,2}$, Mheta Koy ${ }^{1,2}$, Luke R Smart ${ }^{1,2,3}$, Rodrick Kabangila ${ }^{1,2}$, Fiona M Ewings ${ }^{4,5}$, Humphrey D Mazigo ${ }^{6}$, Warren D Johnson $\mathrm{Jr}^{3}$, Daniel W Fitzgerald ${ }^{3}$, Robert N Peck ${ }^{1,2,3}$ and Jennifer A Downs ${ }^{1,2,3}$

\begin{abstract}
Background: Upper gastrointestinal bleeding (UGIB) is a common cause of hospital admissions worldwide. Aetiologies vary by sociodemographics and geography. Retrospective studies of endoscopies in much of Africa have documented oesophageal varices as a leading cause of UGIB. Prospective studies describing outcomes and associations with clinical factors are lacking.

Methods: We conducted a prospective cohort study at a referral hospital in Mwanza, Tanzania where schistosomiasis is endemic. Adults admitted with haematemesis underwent laboratory workup, schistosomiasis antigen testing and elective endoscopy, and were followed for two months for death or re-bleeding. We assessed predictors of endoscopic findings using logistic regression models, and determined prediction rules that maximised sensitivity and positive predictive value (PPV).

Results: Of 124 enrolled patients, 13 died within two months (10\%); active schistosomiasis prevalence was 48\%. 64/91(70\%) patients had oesophageal varices. We found strong associations between varices and numerous demographic or clinical findings, permitting construction of simple, high-fidelity prediction rules for oesophageal varices applicable even in rural settings. Portal vein diameter $\geq 13 \mathrm{~mm}$ or water sourced from the lake yielded sensitivity, specificity, PPV and NPV > 90\% for oesophageal varices; presence of splenomegaly or water sourced from the lake maintained sensitivity and PPV $>90 \%$.

Conclusions: Our results guide identification of patients, via ultrasound and clinical examination, likely to have varices for whom referral for endoscopy may be life-saving. Furthermore, they support empiric anti-schistosome treatment for patients with UGIB in schistosome-endemic regions. These interventions have potential to reduce UGIB-related morbidity and mortality in Africa.
\end{abstract}

Keywords: Upper gastrointestinal bleeding, Schistosomiasis, Tanzania, Mortality, Prospective, Ultrasound

\footnotetext{
*Correspondence: awilchofle12@gmail.com

${ }^{1}$ Department of Internal Medicine, Bugando Medical Centre, Box 1370,

Mwanza, Tanzania

Full list of author information is available at the end of the article
} 


\section{Background}

Upper gastrointestinal bleeding (UGIB), defined as intraluminal bleeding from any location between the upper oesophagus to the duodenum at the ligament of Treitz $[1,2]$, remains a common cause of hospitalisation and death among adults worldwide [3]. In the US, UGIB is responsible for more than 300,000 hospital admissions annually, with a mortality rate of 7-10\% [4]. At our hospital in Tanzania, a diagnosis of schistosomiasis or cirrhosis, which was associated with UGIB in more than $2 / 3$ of patients, was recently documented to be the fourth leading cause of both admissions and deaths in the medicine wards [5].

UGIB can be categorised as oesophageal variceal and non-variceal bleeding. Underlying aetiologies of UGIB vary markedly with geographic region and socioeconomic status [6]. Determination of the aetiology of UGIB is essential for optimising management of these criticallyill patients. Oesophageal band ligation for patients with bleeding oesophageal varices is the ideal treatment that has been shown to reduce mortality [7]. In addition, if the underlying cause of the varices can be determined and is treatable (including infectious aetiologies such as schistosomiasis), pathology leading to oesophageal varices may be diminished.

Two prior retrospective studies in Tanzania, including one at our own hospital, have documented a startlingly high prevalence of variceal bleeding among adults with UGIB $[8,9]$. In these two studies among adults with UGIB who underwent endoscopy, oesophageal varices were present in $51 \%$ and $42 \%$ of patients. These rates contrast with those from other parts of the world in which the prevalence of variceal bleeding among those with UGIB is $<10 \%[10,11]$. Less common aetiologies of UGIB in the Tanzanian studies included duodenal ulcers (14\% and $15 \%)$, gastric ulcers (11\% and $5 \%)$ and gastritis (13\% and $8 \%)$. Of note, both Tanzanian studies were retrospective reviews and therefore did not characterise all patients admitted with UGIB, but only those who were able to afford and undergo endoscopy. In addition, these studies were limited to analysis of data that had been recorded by clinicians in patients' charts.

In this prospective cohort study, we sought to determine aetiologies of UGIB among adults admitted to our hospital and demographic and clinical factors associated with oesophageal varices that would be useful for guiding the diagnosis and management of patients presenting with UGIB to African hospitals where endoscopy is unavailable or unaffordable. We hypothesised that the prevalence of oesophageal varices in this region in which schistosomiasis is hyper-endemic would be comparable to or higher than the prevalence found in prior retrospective studies. We further hypothesised that ongoing active schistosomiasis would a frequent finding and would be associated with oesophageal varices.

\section{Methods}

\section{Study setting}

We aimed to enroll all adult inpatients presenting with haematemesis to our hospital, Bugando Medical Centre $(\mathrm{BMC})$, over a period of six months. BMC is a regional hospital that serves the Lake Zone of north-western Tanzania (population of $\sim 13$ million) and is located in the city of Mwanza. Schistosomiasis is highly endemic in the region, with a documented prevalence of $>50 \%$ in many areas [12-14]. The regional prevalence of chronic Hepatitis $\mathrm{B}$ infection is $\sim 10 \%$ [15]. All adults ( $\geq 14$ years) who reported haematemesis in the past 14 days were interviewed for enrolment. Enrolled patients were followed for two months after the date of admission for death or rebleeding, the time period during which mortality risk is highest [16]. Telephone contact with patients or family members was used to determine outcomes among discharged patients. Rebleeding was defined as recurrent vomiting of fresh blood either with shock or a decrease in haemoglobin concentration of $>2 \mathrm{~g} / \mathrm{dL}$.

\section{Data collection}

Patients were interviewed and examined within 24 hours of admission using a structured questionnaire to collect demographic information, clinical symptoms and physical signs. Initial management of all patients with UGIB at our hospital includes the following: evaluation of cardiovascular status using pulse, blood pressure, and orthostatic changes, confirmation of adequate intravenous access, rapid intravascular volume replacement with fluids and red blood cells, and correction of coagulopathy with platelet concentrate or fresh frozen plasma. For all study patients, ten millilitres of blood were collected for crossmatching and to measure haemoglobin level, platelets, mean corpuscular volume (MCV), international normalised ratio (INR), partial thromboplastin time (PTT), rapid test for HIV, hepatitis B surface antigen (HBsAg), hepatitis $\mathrm{C}$ antibody (HCAb), alanine aminotransferase (ALT), aspartate aminotransferase (AST), total and direct bilirubin, and albumin. Decisions regarding blood transfusion were made by the attending physicians and depended on estimated blood loss, the availability of blood at the blood bank, and the patient's haemoglobin level.

Each patient's urine was tested for circulating cathodic antigen (CCA), an antigen produced by adult schistosome worms that is secreted into the bloodstream and excreted into urine, using a point-of-care test (Rapid Medical Diagnostics, Pretoria, South Africa). The CCA test indicates active schistosome infection and can be positive in the urine during infection with either species of schistosomes that are endemic in Tanzania ( $S$. mansoni and 
S. haematobium), though its sensitivity is lower in $S$. haematobium [17-19]. CCA point-of-care testing is used widely and has been found to be more sensitive than the gold standard Kato-Katz stool diagnosis of Schistosoma mansoni, particularly for lighter infections [20]. Following the manufacturer's instructions, any positive line in the "test" area was considered positive. Line intensities were graded as "1" (test line visible but lighter than control line), "2" (test line equal to control line), and " 3 " (test line darker than control line).

Endoscopy was performed using a Pentax EPM 3500 fiberoptic endoscope (Pentax Medical, Tokyo, Japan) for patients who were able to afford endoscopy ( 100 US dollars). Oesophageal banding was performed for patients who had bleeding varices. Injection with diluted adrenaline was performed for bleeding peptic ulcers.

We also asked patients ten questions derived from Oxford University's Multidimensional Poverty Index (MPI), which is an international measure of poverty relevant to 109 resource-poor countries [21]. The MPI is designed to measure deprivations across the three dimensions of education, health, and standard of living, and persons reporting deficiencies in at least one-third of the measures are considered multidimensionally poor. The questionnaire is scored from zero to six, with six indicating no poverty and scores less than or equal to four indicating multidimensional poverty (Additional file 1: Table S1).

\section{Data analysis}

Data were entered into Microsoft Excel and analysed with Stata/IC Version 12 (College Station, Texas). Categorical variables were summarised by frequency and percentage, and continuous variables by median and interquartile range (IQR). Statistical tests between categorical dependent and independent variables were done using Chi-squared or Fisher's exact tests. We assessed demographic and clinical variables for associations with oesophageal varices using exploratory univariable logistic regression models. Age was categorised as $14-29,30-44,45-59$ and $\geq 60$ years. Occupation and water source were collapsed to binary variables indicating fisherman and water sourced from the lake, respectively. Continuous variables were assumed to have linear effects, and were checked for departures from linearity by categorising and assessing using Wald tests. We also examined continuous variables as binary (normal/abnormal for standard accepted medical values) to facilitate the generation of prediction rules. We created possible prediction rules for oesophageal varices using binary variables which reached $\mathrm{p}<0.05$ and which were immediately ascertainable at the bedside (that is, those requiring laboratory testing were omitted; age was also omitted since there was not a clear linear relationship). We generated rules based on all combinations of these binary variables, using "or" operators. Rules were categorised as clinical only or requiring ultrasound (to measure portal vein diameter). We specified a priori that adequate rules would have sensitivity and positive predictive value (PPV) $\geq 90 \%$, with highest priority given to sensitivity. Rules with specificity and negative predictive value (NPV) $\geq 85 \%$ were preferred. For the sake of parsimony, additional variables were only added to the prediction rules if they improved test characteristics. 95\% confidence intervals (CIs) were estimated using Wilson's formula.

\section{Ethical issues}

Ethical approval was obtained from Bugando Medical Centre and Weill Cornell Medical College. Patients or legal surrogates provided written informed consent for study participation.

\section{Results}

\section{Study population}

Between 1 June and 31 December 2012, 132 adults presented to Bugando with haematemesis. Of these, four died before they could be enrolled, two did not consent for study participation, and two were admitted directly to the Department of Surgery. The remaining 124/132 (94\%) patients were enrolled in our study.

Demographic and medical history information of these 124 patients are presented in Table 1. Patients' median age was 38 (IQR 30-52) years, and the majority (60\%) were male. Many patients were peasants (36\%), Fishermen (14\%) or otherwise self-employed (38\%), and most had received only primary education or less $(83 \%)$. Over a third of patients (35\%) met the criteria for multidimensional poverty. Alcohol use in the past week was reported in 27 (22\%). Fifty patients $(40 \%)$ had been treated with praziquantel previously, while only 47 (38\%) had access to piped water.

\section{Physical and laboratory findings}

Notable physical findings at presentation included the following: splenomegaly in 83 (67\%), ascites in 47 (38\%), abnormally small liver span $(<8 \mathrm{~cm})$ in $24(19 \%)$, haemodynamic instability in $26(21 \%)$, hepatomegaly $(\geq 13 \mathrm{~cm})$ in $18(15 \%)$, and new or worsening encephalopathy in four (3\%). Ultrasound examination confirmed the physical examination finding of splenomegaly in $81 / 83$ cases (97.5\%) and the remaining two cases were borderline by ultrasonographic measurement.

Median admission haemoglobin level was 4.6 (3.8-6.9) $\mathrm{g} / \mathrm{dL}$. Sixty-seven $(54 \%)$ patients had mean corpuscular volumes $<76 \mathrm{fl}$, suggesting chronic blood loss. Forty-six (37\%) patients had abnormal INRs $>1.5$, and $40(32 \%)$ had an elevated total bilirubin level $>17 \mu \mathrm{mol} / \mathrm{L}$. Transaminases were elevated $>40 \mathrm{IU} / \mathrm{L}$ in 33 (27\%). The urine CCA test was positive in 59 patients (48\%). Of these, it was graded as one in 38 patients, two in 14 patients, and three in seven patients. 
Table 1 Demographic Characteristics of 124 Patients Admitted to Bugando Medical Centre with Upper Gastrointestinal Bleeding

\begin{tabular}{|c|c|c|c|}
\hline Variable & Response & $N=124$ & $\%$ \\
\hline Male sex & & 75 & $60 \%$ \\
\hline \multirow[t]{4}{*}{ Age group (years) } & $14-29$ & 30 & $24 \%$ \\
\hline & $30-44$ & 52 & $42 \%$ \\
\hline & $45-59$ & 20 & $16 \%$ \\
\hline & $\geq 60$ & 22 & $18 \%$ \\
\hline Live within $5 \mathrm{~km}$ of the lake & Yes & 80 & $65 \%$ \\
\hline \multirow[t]{5}{*}{ Current occupation } & Peasant & 45 & $36 \%$ \\
\hline & Fisherman & 17 & $14 \%$ \\
\hline & Other self-employed & 47 & $38 \%$ \\
\hline & Civil servant & 9 & $7 \%$ \\
\hline & Student & 6 & $5 \%$ \\
\hline \multirow[t]{4}{*}{ Highest education obtained } & No or less than primary & 26 & $21 \%$ \\
\hline & $\begin{array}{l}\text { Completed primary } \\
\text { education }\end{array}$ & 77 & $62 \%$ \\
\hline & $\begin{array}{l}\text { Completed secondary } \\
\text { education }\end{array}$ & 8 & $6 \%$ \\
\hline & $\begin{array}{l}\text { Any college/university } \\
\text { education }\end{array}$ & 13 & $10 \%$ \\
\hline \multirow[t]{4}{*}{ Source of water } & Piped & 47 & $38 \%$ \\
\hline & Lake & 41 & $33 \%$ \\
\hline & River & 26 & $21 \%$ \\
\hline & $\begin{array}{l}\text { Other (rain water, } \\
\text { wells, dams) }\end{array}$ & 10 & $8 \%$ \\
\hline \multirow[t]{3}{*}{ Poverty index* } & $\leq 2$ & 7 & $6 \%$ \\
\hline & $2.1-4.0$ & 36 & $29 \%$ \\
\hline & $>4.0$ & 81 & $65 \%$ \\
\hline Alcohol use in the past week & Yes & 27 & $22 \%$ \\
\hline $\begin{array}{l}\text { Aspirin or NSAID use in } \\
\text { the past week }\end{array}$ & Yes & 2 & $2 \%$ \\
\hline $\begin{array}{l}\text { Reported history of prior } \\
\text { haematemesis }\end{array}$ & Yes & 47 & $38 \%$ \\
\hline $\begin{array}{l}\text { Reported history of prior } \\
\text { praziquantel treatment }\end{array}$ & Yes & 50 & $40 \%$ \\
\hline
\end{tabular}

*Poverty index $>4$ indicates that a person does not have multidimensional poverty.

\section{Outcomes}

Thirteen of 124 enrolled patients died (10\%): nine (69\%) during the first week, two (15\%) during the second week and two (15\%) during the third and fourth weeks, after they had been discharged. Sixty-two patients (50\%) experienced rebleeding within two months of admission. Of these, 53 (85\%) had in-hospital rebleeding, and the remaining nine $(15 \%)$ had rebleeding that necessitated readmission. Of note, four had severe rebleeding, all from bleeding peptic ulcer disease, and all four underwent surgery. The median transfused units was three (IQR 1-4 units).

\section{Endoscopic findings}

Of 124 patients enrolled in the study, 91 (73\%) underwent endoscopy and received aetiological diagnoses for their haematemesis (Figure 1). Endoscopy was performed at a median of two (IQR 2-5) days. Oesophageal varices were the most common lesions found, affecting 64 (70\%) of patients who underwent endoscopy. The next most common diagnoses were gastric and duodenal ulcers (14 (15\%) and 12 (13\%), respectively).

Among the 13 deaths, seven were in the group of 33 patients who did not have endoscopy, and six were in the 91 patients who did have endoscopy (21\% versus $7 \%$, respectively, $\mathrm{p}=0.02$ ). The odds ratio for death was 3.8 (95\% CI 1.2-12.4; $\mathrm{p}=0.03$ ) for those who did not versus did undergo endoscopy.

\section{Predictors of oesophageal varices}

Factors significantly associated with variceal bleeding on univariable logistic regression analysis included younger age, living within five kilometres of the lake, working as a fisherman, hepatitis B antigen positivity, schistosome CCA positivity, history of praziquantel treatment, lower blood pressure, ascites, splenomegaly, larger portal vein diameter, lower haemoglobin level, lower mean corpuscular volume, and elevated total bilirubin (Table 2). Given the small sample size and some strong predictors of variceal bleeding, it was not possible reliably to estimate multivariable models. For example, the diagnosis for all fishermen was variceal bleeding, and fitting even just bivariable models with factors such as age and portal vein diameter resulted in hugely inflated odds ratios.

\section{Prediction rules for oesophageal varices}

Seven variables met our criteria for inclusion in the prediction rules: living within $5 \mathrm{~km}$ of the lake, fisherman, water sourced from lake, history of praziquantel use, ascites, splenomegaly and portal vein diameter $\geq 13 \mathrm{~mm}$. Considering each alone, splenomegaly and portal vein diameter $\geq$ $13 \mathrm{~mm}$ each met our criteria of sensitivity and PPV $\geq$ 90\% (92 [95\% CI 83-97] and 94 [85-98], respectively, for splenomegaly, and 95 [87-98] and 97 [89-99], respectively, for portal vein diameter $\geq 13 \mathrm{~mm}$; Table 3). Portal vein diameter $\geq 13 \mathrm{~mm}$ offered greater specificity and NPV (93 [77-98] and 89 [73-96], respectively). Considering combinations of variables, 38 met our criteria. Further restricting to those with specificity and NPV $\geq 85 \%$, only one clinicalonly combination remained, namely splenomegaly or water sourced from lake, which yielded some improvement in sensitivity and NPV over splenomegaly alone. Seven further combinations including portal vein diameter $\geq 13 \mathrm{~mm}$ remained; the rule based on portal vein diameter $\geq 13 \mathrm{~mm}$ or water sourced from lake yielded optimal results (sensitivity 98 [92-100], specificity 93 [77-98], PPV 97 [89-99] and NPV 96 [81-99]). 


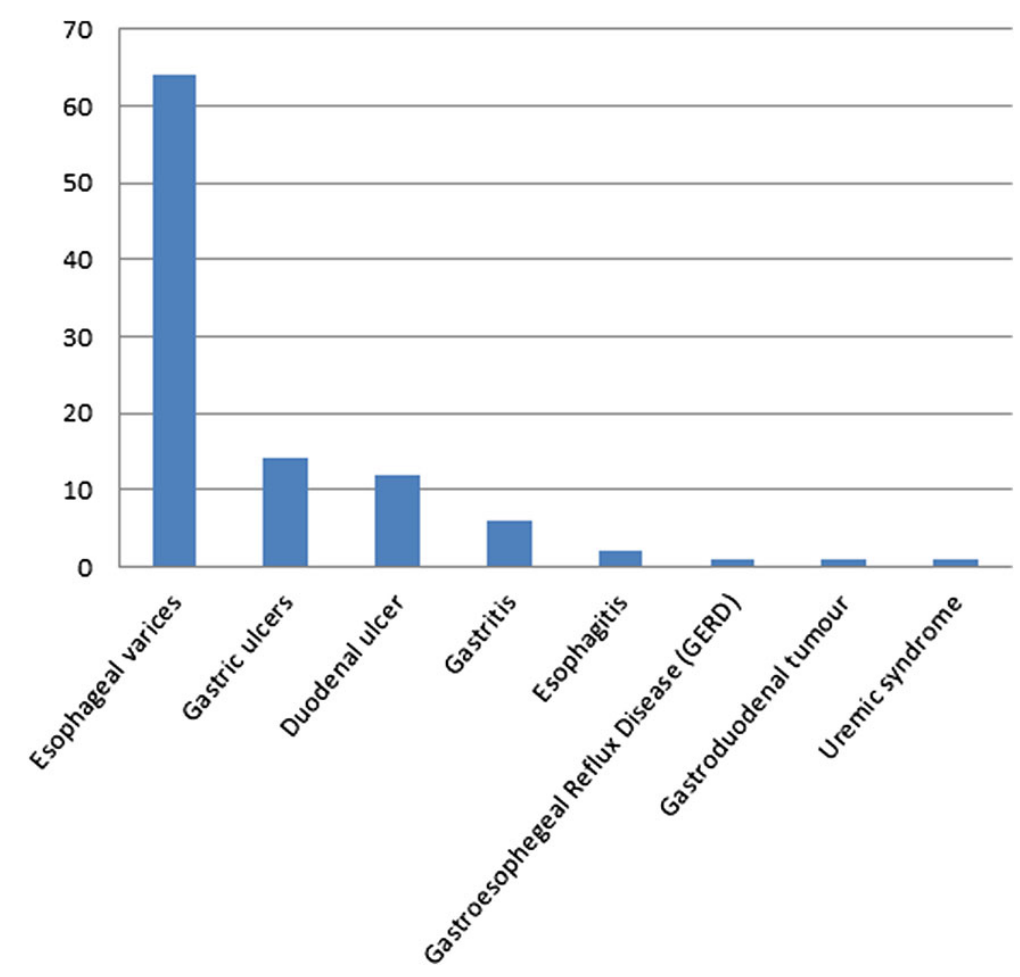

Figure 1 Endoscopically- and/or medically-confirmed aetiologies of upper gastrointestinal bleeding among 91 patients admitted to Bugando Medical Centre.

\section{Discussion}

Our prospective cohort study documents the strikingly high prevalence of variceal bleeding (70\%) among 124 consecutive adult inpatients presenting with haematemesis to a regional hospital in western Tanzania. Moreover, we found that nearly $60 \%$ of patients presenting with haematemesis due to variceal bleeding and 30\% presenting with haematemesis due to other causes had evidence of active schistosomiasis. These results are important for public health in sub-Saharan Africa because they document high rates of a preventable disease. Scaling up efforts to control schistosomiasis could lead to significant reductions in morbidity and mortality among the $\sim 54$ million people living in sub-Saharan Africa who have S. mansoni infection and are at risk for periportal fibrosis, oesophageal varices, and death [22].

To our knowledge, this is the first prospective study to determine endoscopic diagnoses, presenting features, and outcomes among adults with UGIB in East Africa. Two recent retrospective studies done in Tanzania have documented comparably high rates of oesophageal varices among patients with UGIB (41\%-52\%) [8,9]. Our study, conducted in a region in which the prevalence of schistosomiasis is one of the highest in the world, additionally describes numerous factors that were highly associated with oesophageal varices in patients presenting with haematemesis. Associated characteristics included demographics, clinical findings at the time of admission, and documented active infections (hepatitis B and schistosomiasis). Taken together, these data suggest that patients who live near the lakeside and/or fished and present with signs of portal hypertension and liver dysfunction are highly likely to have variceal bleeding.

Identification and appropriate management of patients who have oesophageal varices is urgent because each episode of variceal haemorrhage carries $18-30 \%$ risk of death within six weeks with increasing mortality in the ensuing months and years [23-25]. These mortality estimates are from wealthier settings in which cirrhosis, which is associated with higher mortality, is more common but additional management options such as sclerotherapy and portosystemic shunting are available. We believe that mortality in resource-limited settings, particularly when patients often present with more advanced disease or live remotely from advanced medical care, may be higher. Moreover, endoscopy is a scarce resource in Tanzania, and when combined with transportation expenses, it easily costs over a month's wages for an average rural patient. Therefore, identification of patients most likely to benefit from endoscopy (e.g., those with oesophageal varices that can be banded or sclerosed) is additionally important from a healthcare cost and resource utilisation perspective.

We determined clinical prediction rules with high sensitivity, specificity, PPV, and NPV that can be used in 
Table 2 Demographic and Clinical Predictors of Oesophageal Varices among 91 Patients with Endoscopic Diagnoses

\begin{tabular}{ll}
\hline $\begin{array}{l}\text { Demographic or } \\
\text { clinical parameter }\end{array}$ & $\begin{array}{l}\text { Patients } \\
\text { median }\end{array}$ \\
\hline Sex & $11(41 \%)$ \\
Female & $16(59 \%)$ \\
Male & \\
Age, years & $6(22 \%)$ \\
$15-29$ & $6(22 \%)$ \\
$30-44$ & $3(11 \%)$ \\
$45-59$ & $12(44 \%)$ \\
$\geq 60$ &
\end{tabular}

Live within $5 \mathrm{~km}$ of the lake

No

Yes

Working as a fisherman

No

Yes

Highest education obtained

No or less than primary

Completed primary

Completed secondary

Any college/university

Source of water

Piped/river/other

Lake

Poverty index**

$\leq 4$

$>4$

Alcohol use in the past week

No

Yes

Aspirin/NSAID use in the past week

No

Yes

\section{Prior medical history}

Reported history of prior haematemesis

No

Yes

Reported history of prior praziquantel use

No

Yes

\section{Clinical examination}

Mean arterial blood pressure $(\mathrm{mmHg})$

Heart rate (beats per minute)

Ascites

$19(70 \%)$
$8(30 \%)$

27 (100\%)

0

$48(75 \%)$

$16(25 \%)$

$8(30 \%)$

$12(44 \%)$

$1(4 \%)$

$6(22 \%)$

$27(100 \%)$

0

7 (26\%)

$20(74 \%)$

$19(70 \%)$

$8(30 \%)$

$26(96 \%)$

1 (4\%)

$11(17 \%)$

45 (70\%)

$3(5 \%)$

$5(8 \%)$

31 (48\%)

$33(52 \%)$

$20(31 \%)$

44 (69\%)

53 (83\%)

11 (17\%)

$62(98 \%)$

$1(2 \%)$

21 (78\%)

$6(22 \%)$

36 (56\%)

28 (44\%)

32 (50\%)

32 (50\%)

70 (63-82)

105 (86-111)

98 (88-110)

$24(89 \%)$

No

$32(50 \%)$

1 [reference]
0.06

Univariable odds

.

1 [reference]

1.07 [0.43-2.68]

1 [reference]

3.18 [0.85-11.9]

2.18 [0.44-10.9]

0.27 [0.07-1.10]

$<0.001$

1 [reference]

11.4 [4.00-32.7]

$0.002^{* * *}$

***

1 [reference]

2.73 [0.90-8.29]

2.18 [0.19-25.0]

0.61 [0.14-2.71]

$<0.001^{* * *}$

***

1 [reference]

0.77 [0.28-2.11]

1 [reference]

0.49 [0.17-1.41]

1 [reference]

0.41 [0.02-6.85]

1 [reference]

2.72 [0.97-7.65]

0.008

1 [reference]

4.40 [1.48-13.1]

0.67 [0.49-0.93]+

0.02

1.00 [0.98-1.03]

0.78

0.002 
Table 2 Demographic and Clinical Predictors of Oesophageal Varices among 91 Patients with Endoscopic Diagnoses (Continued)

\begin{tabular}{|c|c|c|c|c|}
\hline Yes & $3(11 \%)$ & $32(50 \%)$ & 8.00 [2.18-29.2] & \\
\hline Hepatomegaly & & & & 0.98 \\
\hline No & $24(89 \%)$ & 57 (89\%) & 1 [reference] & \\
\hline Yes & $3(11 \%)$ & $7(11 \%)$ & $0.92[0.23-4.12]$ & \\
\hline Splenomegaly & & & & $<0.001$ \\
\hline No & $23(85 \%)$ & $5(8 \%)$ & 1 [reference] & \\
\hline Yes & $4(15 \%)$ & 59 (92\%) & 67.9 [16.7-275] & \\
\hline Encephalopathy & & & & 0.54 \\
\hline No & $26(96 \%)$ & $63(98 \%)$ & 1 [reference] & \\
\hline Yes & $1(4 \%)$ & $1(2 \%)$ & $0.41[0.02-6.85]$ & \\
\hline \multicolumn{5}{|l|}{ Investigations } \\
\hline Hepatitis B surface Ag & & & & 0.03 \\
\hline Negative & 25 (93\%) & $45(70 \%)$ & 1 [reference] & \\
\hline Positive & $2(7 \%)$ & 19 (30\%) & $5.27[1.14-24.5]$ & \\
\hline Anti-Hepatitis C Ab & & & & 0.54 \\
\hline Negative & 26 (96\%) & $63(98 \%)$ & 1 [reference] & \\
\hline Positive & $1(4 \%)$ & $1(2 \%)$ & $0.41[0.02-6.85]$ & \\
\hline HIV & & & & 0.63 \\
\hline Negative & $26(96 \%)$ & $60(94 \%)$ & 1 [reference] & \\
\hline Positive & $1(4 \%)$ & $4(6 \%)$ & $1.73[0.18-16.3]$ & \\
\hline Schistosoma CCA & & & & 0.01 \\
\hline Negative & 19 (70\%) & $26(41 \%)$ & 1 [reference] & \\
\hline Positive & $8(30 \%)$ & $38(59 \%)$ & 3.47 [1.32-9.11] & \\
\hline Portal vein, mm & & & & $<0.001$ \\
\hline$<13$ & 25 (93\%) & $3(5 \%)$ & 1 [reference] & \\
\hline$\geq 13$ & $2(7 \%)$ & $61(95 \%)$ & 254 [40.0-1614] & \\
\hline Haemoglobin (g/dL) & $6.0(4.0-9.9)$ & $4.2(3.6-5.6)$ & $0.76[0.64-0.91]$ & 0.002 \\
\hline $\mathrm{MCV}(\mathrm{fl})$ & $82(71-89)$ & $74(67-80)$ & $0.59[0.37-0.92]+$ & 0.02 \\
\hline Platelets $\left(10^{9} / \mathrm{L}\right)$ & $150(103-215)$ & $103(55-143)$ & $0.70[0.45-1.11]++$ & 0.13 \\
\hline PTT (seconds) & $28(26-32)$ & $30(27-35)$ & $1.69[0.75-3.79]+$ & 0.20 \\
\hline INR (ratio) & $1.2(1.0-1.4)$ & $1.4(1.1-1.7)$ & $1.37[0.51-3.63]$ & 0.53 \\
\hline Total bilirubin $(\mu \mathrm{mol} / \mathrm{L})$ & $8.8(5.2-12.7)$ & $13.2(7.7-21.7)$ & $1.07[1.01-1.16]$ & 0.04 \\
\hline Albumin $(\mathrm{g} / \mathrm{L})$ & $35(30-44)$ & $32(28-39)$ & $0.74[0.44-1.24]+$ & 0.25 \\
\hline AST $(U / L)$ & $22(19-29)$ & $28(19-49)$ & $1.23[0.96-1.57]+$ & 0.10 \\
\hline $\mathrm{ALT}(\mathrm{U} / \mathrm{L})$ & $17(14-27)$ & $23(15-47)$ & 1.20 [0.97-1.49] & 0.09 \\
\hline
\end{tabular}

* Results from logistic regression models (Wald p-values).

**Poverty index $>4$ indicates that a person does not have multidimensional poverty.

***Unable to calculate odds ratio due to a zero; $\mathrm{p}$-value from Fisher's exact test.

+ Per 10 units higher.

++ Per 100 units higher.

smaller hospitals where ultrasounds but not endoscopy are available, and in even smaller clinics using history and physical examination alone. When ultrasound is available, the single finding of portal vein diameter $\geq 13 \mathrm{~mm}$ has over $90 \%$ sensitivity, specificity and PPV for oesophageal varices. When ultrasound is not available, the presence of splenomegaly alone maintains a sensitivity and PPV $>90 \%$, allowing focused use of the scarce resource of endoscopy for patients in whom intervention is possible. These clinical rules therefore represent a powerful tool that can be used to suggest which patients with haematemesis are highly likely to have oesophageal varices. These patients 
Table 3 Possible Prediction Rules for Oesophageal Varices

\begin{tabular}{|c|c|c|c|c|}
\hline Rule & Sensitivity $(95 \% \mathrm{Cl})$ & Specificity $(95 \% \mathrm{Cl})$ & PPV (95\% CI) & NPV (95\% Cl) \\
\hline \multicolumn{5}{|l|}{ Single clinical condition: } \\
\hline Splenomegaly & $92(83-97)$ & $85(68-94)$ & $94(85-98)$ & $82(64-92)$ \\
\hline Live within $5 \mathrm{~km}$ of the lake & $83(72-90)$ & $70(52-84)$ & $87(76-93)$ & $63(46-78)$ \\
\hline Water sourced from lake & $52(40-63)$ & $100(88-100)$ & $100(90-100)$ & $47(34-59)$ \\
\hline Ascites & $50(38-62)$ & $89(72-96)$ & $91(78-97)$ & $43(31-56)$ \\
\hline History of praziquantel & $50(38-62)$ & $81(63-92)$ & $86(72-94)$ & $41(29-54)$ \\
\hline Fisherman & $25(16-37)$ & $100(88-100)$ & $100(81-100)$ & $36(26-47)$ \\
\hline \multicolumn{5}{|l|}{ Ultrasound single condition: } \\
\hline Portal vein diameter $\geq 13 \mathrm{~mm}$ & $95(87-98)$ & $93(77-98)$ & $97(89-99)$ & $89(73-96)$ \\
\hline \multicolumn{5}{|l|}{ Combinations of clinical conditions: } \\
\hline Splenomegaly or water sourced from lake & $94(85-98)$ & $85(68-94)$ & $94(85-98)$ & $85(68-94)$ \\
\hline \multicolumn{5}{|l|}{ Combinations of clinical and ultrasound conditions: } \\
\hline Portal vein diameter $\geq 13 \mathrm{~mm}$ or water sourced from lake & $98(92-100)$ & $93(77-98)$ & $97(89-99)$ & $96(81-99)$ \\
\hline Portal vein diameter $\geq 13 \mathrm{~mm}$ or water sourced from lake or ascites & $98(92-100)$ & $89(72-96)$ & $95(87-98)$ & $96(80-99)$ \\
\hline Portal vein diameter $\geq 13 \mathrm{~mm}$ or fisherman & $95(87-98)$ & $93(77-98)$ & 97 (89-99) & $89(73-96)$ \\
\hline Portal vein diameter $\geq 13 \mathrm{~mm}$ or ascites & $95(87-98)$ & $89(72-96)$ & $95(87-98)$ & $89(72-96)$ \\
\hline
\end{tabular}

This table shows single-condition rules and rules which met our primary criteria of sensitivity and PPV $\geq 90 \%$, and additionally had specificity and NPV $\geq 85 \%$.

should be referred for urgent endoscopy and counselled that endoscopy may be life-saving.

Our data demonstrates active schistosome infection in nearly half of adults presenting with haematemesis. Similar rates of schistosomiasis in community-based studies of adults in this region have also been documented [12-14]. These results contrast with the common teaching in subSaharan Africa that schistosomiasis is predominantly an infection of children and that adults presenting with UGIB due to schistosomiasis have past but not present infection. The prevalence of schistosomiasis in endemic regions peaks between age ten and 20, and adults can develop partial immunity but many still remain infected [26,27]. For this reason, we advocate universal testing and treatment for schistosomiasis and/or empiric anti-schistosome treatment as an integral component of managing patients who present with UGIB in schistosome-endemic settings, particularly given the evidence that schistosomal liver pathology will continue to worsen in the setting of ongoing schistosome infection but may regress following antischistosome treatment $[28,29]$.

In addition, our findings suggest that current schistosomiasis control efforts in Tanzania and many other countries in sub-Saharan Africa are inadequate. Many nations with limited healthcare funds focus schistosomiasis treatment efforts on schoolchildren despite the World Health Organization's recommendations that both children and adults living in highly-endemic areas should be treated annually for schistosomiasis [30]. The average lifespan of the S. mansoni worm is $3-5$ years, while the time from infection to development of liver fibrosis typically takes 5-15 years [26]. Therefore, the finding of active schistosomiasis in these adults presenting with end-stage liver fibrosis suggests that they have been subject to ongoing exposure and re-infection for many years. In the absence of the ability to eliminate schistosomiasis altogether through behavioural change, clean water provision, and improved sanitation, the next-best remedy is to decrease worm burden and morbidity through routine treatment for both children and adults.

Our study has several limitations. First, we were not able to perform liver biopsies in this resource-limited setting in order to corroborate our diagnoses histopathologically. The ability to do so would have been most useful to determine the predominant disease in the 11 patients who had both active schistosome infection and Hepatitis B antigen positivity. Second, we limited our study population to patients with haematemesis in the past 14 days in order to ensure that only patients with true upper gastrointestinal bleeding were enrolled. It is possible that this led to the exclusion of patients with less acute or lower-volume upper gastrointestinal bleeding.

\section{Conclusions}

In conclusion, our prospective data reveals extremely high rates of oesophageal varices and active schistosomiasis among adults presenting with haematemesis to a referral hospital in a region in which both schistosomiasis and hepatitis B are endemic. Oesophageal varices were strongly associated with specific ultrasonographic and physical examination findings that can be assessed even in the most rural hospitals. Our data provides guidance for 
identification of patients likely to have varices for whom referral for endoscopy may be life-saving, and it also supports empiric praziquantel treatment for patients in lowresource, schistosome-endemic regions who present with UGIB. Both of these simple interventions have the potential to reduce morbidity and mortality associated with UGIB in sub-Saharan Africa.

\section{Additional file}

Additional file 1: Table S1. Supplementary Material: Multidimensional Poverty Index.

\begin{abstract}
Abbreviations
ALT: Alanine aminotransferase; AST: Aspartate aminotransferase; BMC: Bugando Medical Centre; CCA: Circulating cathodic antigen; HBsAg: Hepatitis B surface antigen; HCAb: Hepatitis C antibody; INR: International normalized ratio; IQR: Interquartile range; MCV: Mean corpuscular volume; MPI: Multidimensional poverty index; NPV: Negative predictive value; PPV: Positive predictive value; PTT: Partial thromboplastin time; UGIB: Upper gastrointestinal bleeding.
\end{abstract}

\section{Competing interests}

The authors declare that they have no competing interests.

\section{Authors' contributions}

Designed the study: AC, HJ, MK, HM, RP, JD. Data Collection: AC, HJ, MK. Data Analysis: AC, LS, FE, DF, RP, JD. Data Interpretation: AC, FE, WJ, DF, RP, JD. Manuscript preparation: AC, HJ, MK, LS, RK, FE, HM, WJ, DF, RP, JD. All authors read and approved the final manuscript.

\section{Acknowledgements}

We thank Bugando Medical Centre and particularly Prof. Charles Majinge for supporting this study. Schistosomiasis CCA rapid tests were purchased through a grant from the National Institutes of Health Fogarty International Center (TW00018). Authors' funding sources: Bugando Medical Centre (AC, HF, MK, RK, HM); National Institutes of Health Fogarty International Center (LS, WJ, DF, RP, JD); London School of Hygiene and Tropical Medicine (FE). The funders had no role in the design, data collection, analysis, interpretation of data, writing of the manuscript, or in the decision to submit the manuscript for publication.

\section{Author details}

'Department of Internal Medicine, Bugando Medical Centre, Box 1370, Mwanza, Tanzania. ${ }^{2}$ Department of Internal Medicine, Catholic University of Health and Allied Sciences-Bugando, Mwanza, Tanzania. ${ }^{3}$ Department of Medicine, Weill Cornell Medical College, New York, USA. ${ }^{4}$ Department of Infectious Disease Epidemiology, London School of Hygiene and Tropical Medicine, London, United Kingdom. ' Mwanza Interventional Trials Unit, Mwanza, Tanzania. ${ }^{6}$ Department of Parasitology, Catholic University of Health and Allied Sciences - Bugando, Mwanza, Tanzania.

Received: 9 August 2013 Accepted: 13 May 2014

Published: 3 June 2014

\section{References}

1. Bush EL, Shapiro ML: Gastrointestinal Bleeding: A Practical Approach to Diagnosis and Management. New York: Springer: Pryor AD, Pappas TN, Branch MS; 2010:223.

2. Laine L: Harrison's Principles of Internal Medicine. 17th edition. Edited by Fauci A, Kasper D, Longo D, Braunwald E, Hauser S, Jameson J, Loscalzo J. New York: McGraw-Hill; 2008:2958.

3. Theocharis GJ, Thomopoulos KC, Sakellaropoulos G, Katsakoulis E, Nikolopoulou V: Changing trends in the epidemiology and clinical outcome of acute upper gastrointestinal bleeding in a defined geographical area in Greece. J Clin Gastroenterol 2008, 42:128-133.
4. Van Leerdam ME, Vreeburg EM, Rauws EAJ, Geraedts AAM, Tijssen JGP, Reitsma JB, Tytgat GNJ: Acute upper GI bleeding: did anything change? Time trend analysis of incidence and outcome of acute upper $\mathrm{Gl}$ bleeding between 1993/1994 and 2000. Am J Gastroenterol 2003, 98:1494-1499.

5. Peck RN, Green E, Mtabaji J, Majinge C, Smart LR, Downs JA, Fitzgerald DW: Hypertension-related diseases as a common cause of hospital mortality in Tanzania: a 3-year prospective study. J Hypertens 2013, 31:1806-1811.

6. Elghuel A: The characteristics of adults with upper gastrointestinal bleeding admitted to Tripoli Medical Center: a retrospective case-series analysis. Libyan J Med 2011, 6:1-5.

7. Laine L, Cook D: Endoscopic ligation compared with sclerotherapy for treatment of esophageal variceal bleeding. A meta-analysis. Ann Intern Med 1995, 123:280-287.

8. Suba M, Ayana SM, Mtabho CM, Kibiki GS: The aetiology, management and clinical outcome of upper gastrointestinal bleeding among patients admitted at the Kilimanjaro Christian Medical Centre in Moshi, Tanzania. Tanzania J Heal Res 2010.

9. Jaka H, Koy M, Liwa A, Kabangila R, Mirambo M, Scheppach W, Mkongo E, McHembe MD, Chalya PL: A fibreoptic endoscopic study of upper gastrointestinal bleeding at Bugando Medical Centre in northwestern Tanzania: a retrospective review of 240 cases. BMC Res Notes 2012, 5:200.

10. Loperfido S, Baldo V, Piovesana E, Bellina L, Rossi K, Groppo M, Caroli A, Dal Bò N, Monica F, Fabris L, Salvat HH, Bassi N, Okolicsanyi L: Changing trends in acute upper-Gl bleeding: a population-based study. Gastrointest EndosC 2009, 70:212-24

11. Hreinsson JP, Kalaitzakis E, Gudmundsson S, Björnsson ES: Upper gastrointestinal bleeding: incidence, etiology and outcomes in a population-based setting. Scand J Gastroenterol 2013, 48:439-47.

12. Clements AC a, Lwambo NJS, Blair L, Nyandindi U, Kaatano G, Kinung'hi S, Webster JP, Fenwick A, Brooker S: Bayesian spatial analysis and disease mapping: tools to enhance planning and implementation of a schistosomiasis control programme in Tanzania. Trop Med Int Heal 2006, 11:490-503.

13. Mazigo HD, Nuwaha F, Kinung'hi SM, Morona D, Pinot de Moira A, Wilson S, Heukelbach J, Dunne DW: Epidemiology and control of human schistosomiasis in Tanzania. Parasit Vectors 2012, 5:274.

14. Downs J, Van Dam G, Changalucha J, Corstjens P, Peck R, De Dood C, Bang $H$, Andreasen A, Kalluvya S, Van Lieshout L, Johnson WJ, Fitzgerald D: Association of Schistosomiasis and HIV infection in Tanzania. Am J Trop Med Hyg 2012, Nov, 87:868-73.

15. Jacobs B, Mayaud P, Changalucha J, Todd J, Ka-Gina G, Grosskurth HBZ: Sexual transmission of hepatitis B in Mwanza. Sex Transm Dis 1997, 24:121-126.

16. Smith JL, Graham DY: Variceal hemorrhage: a critical evaluation of survival analysis. Gastroenterology 1982, 82(5 Pt 1):968-73.

17. Obeng BB, Aryeetey YA, De Dood CJ, Amoah AS, Larbi IA, Deelder AM, Yazdanbakhsh M, Hartgers FC, Boakye DA, Verweij JJ, Van Dam GJ, Van Lieshout L: Application of a circulating-cathodic-antigen (CCA) strip test and real-time PCR, in comparison with microscopy, for the detection of Schistosoma haematobium in urine samples from Ghana. Ann Trop Med Parasitol 2008, 102:625-33.

18. Stothard JR, Sousa-Figueiredo JC, Standley C, Van Dam GJ, Knopp S, Utzinger J, Ameri H, Khamis AN, Khamis IS, Deelder AM, Mohammed KA, Rollinson D: An evaluation of urine-CCA strip test and fingerprick blood SEA-ELISA for detection of urinary schistosomiasis in schoolchildren in Zanzibar. Acta Trop 2009, 111:64-70.

19. Ashton RA, Stewart BT, Petty N, Lado M, Finn T, Brooker S, Kolaczinski JH: Accuracy of circulating cathodic antigen tests for rapid mapping of Schistosoma mansoni and S. haematobium infections in Southern Sudan. Trop Med Int Heal 2011, 16:1099-103.

20. Colley DG, Binder S, Campbell C, King CH, Tchuem Tchuenté L-A, N'Goran EK, Erko B, Karanja DMS, Kabatereine NB, Van Lieshout L, Rathbun S: A five-country evaluation of a point-of-care circulating cathodic antigen urine assay for the prevalence of Schistosoma mansoni. PLoS Negl Trop Dis 2013, 7(1):e2008. doi 10137 2013, 88:426-32.

21. Oxford Poverty \& Human Development Initiative (OPHI). http://www.ophi.org.uk/.

22. Van der Werf MJ, De Vlas SJ, Brooker S, Looman CWN, Nagelkerke NJD, Habbema JDF, Engels D: Quantification of clinical morbidity associated 
with schistosome infection in sub-Saharan Africa. Acta Trop 2003, 86:125-39.

23. Chalasani N, Kahi C, Francois F, Pinto A, Marathe A, Bini EJ, Pandya P, Sitaraman S, Shen J: Improved patient survival after acute variceal bleeding: a multicenter, cohort study. Am J Gastroenterol 2003, 98:653-9.

24. Limquiaco J, Nolasco ER, Daez MLO, Gloria VI, Domingo EO, Banez VP, Zano FM, Atienza MA, Sy PP, Labio E, Comia AC, De Lusong MAA, Jun P, Sherwin F, Elmer Cabanayan PAP: Clinical predictors of bleeding from esophageal varices. Phil J Gastroenterol 2006, 2:103-111.

25. Thomopoulos K, Theocharis G, Mimidis K, Lampropoulou-Karatza C, Alexandridis E, Nikolopoulou V: Improved survival of patients presenting with acute variceal bleeding. Prognostic indicators of short- and long-term mortality. Dig Liver Dis 2006, 38:899-904.

26. Gryseels B, Polman K, Clerinx J, Kestens L: Human schistosomiasis. Lancet 2006, 368:1106-18

27. Woolhouse ME, Taylor P, Matanhire D, Chandiwana SK: Acquired immunity and epidemiology of Schistosoma haematobium. Nature 1991, 351:757-9.

28. Andrade ZA, Baptista AP, Santana TS: Remodeling of hepatic vascular changes after specific chemotherapy of schistosomal periportal fibrosis. Mem Inst Oswaldo Cruz 2006, 101Suppl(Popper 1977):267-72.

29. Vennervald B, Booth M, Butterworth A, Kariuki H, Kadzo H, Ireri E, Amaganga C, Kimani G, Kenty L, Mwatha J, Ouma J, Dunne D: Regression of hepatosplenomegaly in. Trans R Soc Trop Med Hyg 2005, 99:150-160.

30. Schistosomiasis: Epidemiological Situation. http://www.who.int/ schistosomiasis/epidemiology/en.

doi:10.1186/1471-2334-14-303

Cite this article as: Chofle et al.: Oesophageal varices, schistosomiasis, and mortality among patients admitted with haematemesis in Mwanza, Tanzania: a prospective cohort study. BMC Infectious Diseases 2014 14:303.

\section{Submit your next manuscript to BioMed Central and take full advantage of:}

- Convenient online submission

- Thorough peer review

- No space constraints or color figure charges

- Immediate publication on acceptance

- Inclusion in PubMed, CAS, Scopus and Google Scholar

- Research which is freely available for redistribution 